\title{
Comparison of Long Term Oxygen-Therapy (LTOT) and LTOT Combined with Sildenafil and Simvastatin in the Treatment of Severe Chronic Obstructive Pulmonary (COPD) with Hypoxia at Rest and Severe Pulmonary Arterial Hypertension
}

\section{Huong Tran-Van ${ }^{1}$, Anh Vo-Thi-Kim ${ }^{2}$, T Tran-Ngoc ${ }^{3}$ and Sy Duong-Quy ${ }^{3,4,5 *}$}

${ }^{1}$ Department of Health Science, Thang Long University, Hanoi, Vietnam

${ }^{2}$ Nam Anh General Hospital, Binh Duong Province, Vietnam

${ }^{3}$ Bio-Medical Research Center, Lam Dong Medical College, Dalat, Vietnam

${ }^{4}$ Department of Cardio-Pulmonology Functional Testing, Cochin Hospital, Paris Descartes University, France

${ }^{5}$ Penn State College of Medicine, Hershey, PA 17033, USA

\begin{abstract}
Background: Pulmonary arterial hypertension is frequent in patients with severe chronic obstructive pulmonary disease (COPD). It increases the morbidity and mortality of patients with advanced stage of COPD. The use of long-term oxygen therapy (LTOT) and some other vasodilators seems necessary to prevent pulmonary arterial hypertension (PAH) and right heart failure in these patients.
\end{abstract}

Objective: This study was planned to compare the effect of LTOT alone and LTOT combined with sildenafil (PDE-5 inhibitor) and simvastatin (HMG CoA reductase inhibitor) on pulmonary arterial pressure of patients with severe COPD having hypoxia at rest.

Methods: It was a cross-sectional and comparative study. All patients with severe COPD having hypoxia at rest $\left(\mathrm{SpO}_{2}<88 \%\right)$ had been classified in three groups: Group 1 (treated with LTOT), Group 2 (treated with LTOT+sildenafil), and Group 3 (treated with LTOT+sildenafil+simvastatin). All study patients had been treated with conventional therapy (long-acting beta2-agonists+inhaled corticosteroids+long-acting muscarinic antagonists) and followed up during 6 months with one visit every three months. The mean systolic pulmonary arterial pressures (PAP) had been measured by transthoracic echocardiography (TTE).

Results: Ninety-eight patients with severe COPD and hypoxia at rest were included in this study (Group 1:32 patients, Group 2:35 patients, and Group 3:31 patients). The systolic PAPs and diffusing capacity of the lungs for carbon monoxide (DLCO) were significantly ameliorated after 3 to 6 months. The mean systolic PAP in patients from Group 2 and Group 3 were significantly lower than that in Group 1 at 3 months $(41 \pm 9 \mathrm{mmHg}$ and $39 \pm 7$ $\mathrm{mmHg}$ vs. $46 \pm 10 \mathrm{mmHg} ; \mathrm{P}<0.05$ and $\mathrm{P}<0.05$; respectively). After 6 months, oxygen consumption $\left(\mathrm{VO}_{2} \max \right)$ and 6 minutes walking distances were significantly increased in patients from Group 2 and Group $3(P<0.05$ and $P<0.05$; respectively).

Conclusion: LTOT is an efficacy treatment for severe COPD patients with hypoxia at rest and PAH. Sildenafil and simvastatin have some additional effect on the reduction of PAP and physical exercise capacity.

Keywords: COPD; Hypoxia; Pulmonary hypertension; Sildenafil; Simvastatin

\section{Introduction}

COPD is a leading cause of morbidity and mortality worldwide that provides a strong economic and social burden for all countries $[1,2]$. The prevalence and mortality of COPD vary across different populations and countries. In emergent countries, the prevalence of COPD is mainly related to tobacco smoking, although indoor air pollution from exposing the burning of biomass fuels are also the risk of COPD [3-5].

One of the main important complications of patients with COPD is pulmonary arterial hypertension (PAH). $\mathrm{PAH}$ appears usually in advanced stage of COPD where the airflow obstruction becomes more severe. Although new pathophysiological mechanisms of PAH in subjects with COPD have been proposed recently, which related to chronic alveolar hypoxia-induced vasoconstriction and vascular remodeling are still the main mechanism [6]. Previous studies showed that there was the correlation between increased pulmonary arterial pressure (PAP) and survival prognostic in patients with severe COPD
[7]. In severe COPD patients, the PAP might be measured preferably by non-invasive method with the use of transthoracic echocardiography (TTE)

The existence of PAH in subjects with COPD is one of the criteria for prescribing long-term oxygen therapy (LTOT). LTOT may prevent a worsening progression of increased PAP and its repercussion on right ventricular function. Currently, LTOT is easily to access for

*Corresponding author: Professor Sy Duong-Quy, MD, PhD, FCCP, Cochin Hospital. Paris Descartes University, Penn State Medical College, USA, Tel: +0033679193377; E-mail: sduongquy.jfvp@gmail.com

Received July 07, 2017; Accepted July 18, 2017; Published July 20, 2017

Citation: Tran-Van H, Vo-Thi-Kim A, Tran-Ngoc T, Duong-Quy S (2017) Comparison of Long Term Oxygen-Therapy (LTOT) and LTOT Combined with Sildenafil and Simvastatin in the Treatment of Severe Chronic Obstructive Pulmonary (COPD) with Hypoxia at Rest and Severe Pulmonary Arterial Hypertension. J Vasc Med Surg 5: 324. doi: 10.4172/2329-6925.1000324

Copyright: (c 2017 Tran-Van H, et al. This is an open-access article distributed under the terms of the Creative Commons Attribution License, which permits unrestricted use, distribution, and reproduction in any medium, provided the original author and source are credited. 
Citation: Tran-Van H, Vo-Thi-Kim A, Tran-Ngoc T, Duong-Quy S (2017) Comparison of Long Term Oxygen-Therapy (LTOT) and LTOT Combined with Sildenafil and Simvastatin in the Treatment of Severe Chronic Obstructive Pulmonary (COPD) with Hypoxia at Rest and Severe Pulmonary Arterial Hypertension. J Vasc Med Surg 5: 324. doi: 10.4172/2329-6925.1000324

Page 2 of 6

patients with COPD in advanced stage and even though for those who are living in developing countries. However, the new insights into the pathophysiology of PAH related to COPD suggest some potential target therapies that aim to stabilize the pulmonary hemodynamic and vascular remodelling in these patients [8]. Among them, the effect of type 5 phosphodiesterase (PDE-5) inhibitors and non-selective RhoA/Rho-kinase inhibitors such as statins has been demonstrated recently $[9,10]$. Statins, the 3-hydroxy-3-methylglutaryl CoA reductase inhibitors, reduce RhoA activation by preventing post-translational isoprenylation of the protein and its translocation to the plasma membrane [11]. This effect reduces pulmonary vasoconstriction in different causes of hypoxia-induced PAH.

However, the role of LTOT in association with PDE- 5 and statin, a non-selective RhoA/Rho-kinase inhibitor, in the treatment of PAH for subjects with severe COPD has not been clarified. This study was planned to demonstrate the effect of LTOT vs. LTOT combined with sildenafil, a PDE-5 inhibitor, or statin in patients with severe COPD having hypoxia at rest and $\mathrm{PAH}$.

\section{Patients and Methods}

\section{Patients}

COPD patients with PAH diagnosed by TTE (transthoracic echocardiography) were included in the present study after signing an Institutional Review Board (IRB) approved consent and meeting the inclusion and exclusion criteria. The present study had been approved by LMC (Lam Dong Medical College) Institutional Review Board.

Exclusion criteria: Study subjects having one of the following criteria were excluded from the study: acute or sub-acute myocardial infarction; decompensated heart failure or uncontrolled high blood pressure; COPD with severe exacerbations due to low airway infection requiring management in the Intensive Care Unit; current treatment with LTOT, PDE-5 inhibitors or statins; severe disorders of liver function; unable to perform the functional or biological testing required by study protocol.

Inclusion criteria: Stable and severe COPD with $\mathrm{PAH}$, diagnosed by TTE, having severe resting hypoxemia $\left(\mathrm{SpO}_{2}<88 \%\right)$ were included in the present study. They were randomly divided into three groups based on PAH treatment: Group 1: treated with conventional therapy (CT) recommended by GOLD combined with LTOT; Group 2: treated with CT combined with LTOT and sildenafil; Group 3: treated with CT combined with sildenafil and simvastatin.

\section{Methods}

Study design: It was a cross-sectional, descriptive, and comparative study. All data on medical history, clinical examination, and laboratory tests were collected for statistical analyses. The study subjects were followed up during six months. The conventional treatment was included LABA (long- acting beta ${ }_{2}$-agonists) associated with ICS (inhaled corticosteroids), LAMA (long-acting muscarinic antagonists), and SABA (short-acting beta ${ }_{2}$-agonists) as needed. LTOT was prescribed for patients who had severe resting hypoxemia $\left(\mathrm{SpO}_{2}<88 \%\right)$ to assure $90 \%<\mathrm{SpO}_{2}<95 \%$ with the use of LTOT $>15$ hours/day (during sleep and in day time or whole day) $[12,13]$. Sildenafil $50 \mathrm{mg}$ twice a day was prescribed for patients from Group 2 and Group 3 in combined with conventional treatment (CT). Simvastatin $20 \mathrm{mg}$ one a day was prescribed to patients of Group 3.

\section{Laboratory techniques}

Pulmonary function test: Lung function testing was done by Body Box 500 (Medisoft, Sorinnes, Belgium) for whole-body phlethysmography. The reversibility of $\mathrm{FEV}_{1}$ (forced expiratory volume in one second) was evaluated after $15 \mathrm{~min}$ post-BD with $400 \mu \mathrm{g}$ of salbutamol. The airflow limitation was considered reversible when the increase of $\mathrm{FEV}_{1} \geq 12 \%$ and $200 \mathrm{~mL}$. The measure of diffusing capacity of the lungs for carbon monoxide (DLCO) was performed by standard recommended guidelines of the American Thoracic Society (ATS)/ European Respiratory Society (ERS) [14,15].

Six-Minute walking test (6MWT): All study subjects performed the 6MWT and $\mathrm{VO}_{2}$ max test at inclusion and after 3 months and 6 months of follow up. The 6MWT was accomplished as recommended by ATS [16]. The 6-minute walk distance (6MWD) and the change of oxygen desaturation were collected for analyses.

Maximal oxygen consumption test $\left(\mathrm{VO}_{2} \max \right): \mathrm{VO}_{2} \max$ was performed by using an Ergo Card (Medisoft). It was based on the symptom-limited physical exercise test with ventilatory expired gas analysis using a cycle ergometer. The workload from 5 Watts to 10 Watts or 15 Watts/minute protocol had been adapted for each study subject to obtain at least $8 \mathrm{~min}$ (with $2 \mathrm{~min}$ of warming up for the first step) of exercise duration as recommended previously [17]. The peak of oxygen consumption uptake $\left(\mathrm{VO}_{2} \max \right)$ was used for comparing the exercise capacity of study patients at inclusion and after 3 and 6 months.

Transthoracic echocardiography (TTE): Transthoracic echocardiography provided pulmonary arterial pressure (PAP) in all study patients. The estimation of PAP was based on the peak velocity of the jet of tricuspid regurgitation by using the simplified Bernoulli equation [18]. The PA systolic pressure (sys PAP) $>50 \mathrm{mmHg}$ measured by TTE was used to diagnose PAH in COPD subjects [19].

Statistical analyses: All collected data were analyzed by SPSS 22.0 software (Chicago; USA). Categorical variables were expressed as numbers or percentages. Continuous variables were presented as mean \pm SD. The pair-comparison of mean using Mann-Whitney U test and more than two groups with Kruskal-Wallis test. The $\mathrm{P}$ value $<0.05$ was considered as significant.

\section{Results}

\section{Clinical and functional characteristics of study subjects at inclusion}

From January 2016 to Mars 2017, 98 patients with severe COPD were included in the present study. They had been randomly classified in three different groups as described previously:

Group 1: Patients had been planned to be treated with conventional therapy recommended by GOLD [20], combined with long-term oxygen therapy (LTOT);

Group 2: Patients had been selected for treating with conventional therapy combined with LTOT and sildenafil $50 \mathrm{mg}$ twice per day;

Group 3: Patients had been randomized for treating with conventional therapy combined with LTOT, sildenafil $50 \mathrm{mg}$ twice per day, and simvastatin $20 \mathrm{mg}$ one per day.

In the present study, there were no significant differences between 3 groups for age, male/female percentage, and BMI (Table 1). The tobacco consumption was not significantly different between 3 groups 
Citation: Tran-Van H, Vo-Thi-Kim A, Tran-Ngoc T, Duong-Quy S (2017) Comparison of Long Term Oxygen-Therapy (LTOT) and LTOT Combined with Sildenafil and Simvastatin in the Treatment of Severe Chronic Obstructive Pulmonary (COPD) with Hypoxia at Rest and Severe Pulmonary Arterial Hypertension. J Vasc Med Surg 5: 324. doi: 10.4172/2329-6925.1000324

Page 3 of 6

(Table 1). There was any patient with mMRC (Modified British Medical Research Council) at grade $0-2$ in 3 groups. The score of mMRC and the times of previous hospitalization were not significantly different between study groups (Table 1).

The mean systolic pulmonary arterial pressures (PAP) had been measured by transthoracic echocardiography (TTE) confirming pulmonary arterial hypertension $(\mathrm{PAH})$. They were not significantly different between study groups $(58 \pm 8 \mathrm{mmHg}$ vs. $60 \pm 9 \mathrm{mmHg}$ and $59 \pm 7$ mmHg; $P>0.05, \mathrm{P}>0.05$, and $\mathrm{P}>0.05$; respectively; Table 1$)$. All the patients had severe airway obstruction with $30 \%<\mathrm{FEV}_{1}<50 \%$ and $\mathrm{FEV}_{1} / \mathrm{FVC}$ ratio $<70 \%$. They also had the moderate decrease of DLCO $(44 \pm 13 \%, 43 \pm 12 \%$, and $42 \pm 14 \%$; respectively; Table 1$)$. There were no significant differences between 3 groups for maximal oxygen consumption $\left(\mathrm{VO}_{2}\right.$ max: $34 \pm 8 \%$ vs. $32 \pm 10 \%$ and $36 \pm 9 \%$; $>0.05$, $\mathrm{P}>0.05$, and $\mathrm{P}>0.05$; respectively; Table 1$)$ and 6 minutes walking distances (6MWD: $212 \pm 86 \mathrm{~m}$ vs. $224 \pm 74 \mathrm{~m}$ and $217 \pm 95 \mathrm{~m} ; \mathrm{P}>0.05$, $\mathrm{P}>0.05$, and $\mathrm{P}>0.05$; respectively; Table 1$)$.

\section{Effect of sildenafil combined with simvastatin and LTOT in association with conventional treatment after 3 months}

The results showed that patients treated with conventional therapy combined with LTOT, sildenafil $100 \mathrm{mg}$, and simvastatin $20 \mathrm{mg}$ (Group 3) had the percentage of mMRC grade 3 was significant higher and $\mathrm{mMRC}$ grade 4 was significant lower than two other groups $(62.7 \%$ vs. $53.6 \%$ and $55.4 \% ; 37.3 \%$ vs. $46.4 \%$ and $44.6 \% ; \mathrm{P}<0.05$ and $\mathrm{P}<0.05$; respectively; Table 2); while there was no significant difference between Group 2 (treated with conventional therapy combined with LTOT and

\begin{tabular}{|c|c|c|c|c|}
\hline Parameters & $\begin{array}{l}\text { Group } 1 \\
\mathrm{~N}=32\end{array}$ & $\begin{array}{l}\text { Group } 2 \\
\mathrm{~N}=35\end{array}$ & $\begin{array}{l}\text { Group } 3 \\
\mathrm{~N}=31\end{array}$ & $\mathbf{P}$ \\
\hline Age, years & $61 \pm 8$ & $63 \pm 7$ & $62 \pm 9$ & $\mathrm{NS}^{*},{ }^{* *},{ }^{* * *}$ \\
\hline Male/Female, \% & 90.7 & 91.5 & 93.6 & $\mathrm{NS}^{*},{ }^{* * * * *}$ \\
\hline BMI, $\mathrm{kg} / \mathrm{m}^{2}$ & $22.4 \pm 4.3$ & $21.7 \pm 3.7$ & $22.6 \pm 3.4$ & $\mathrm{NS}^{*},{ }^{* *},{ }^{* * *}$ \\
\hline Tobacco consumption, pack-year & $39 \pm 7$ & $37 \pm 9$ & $40 \pm 8$ & $\mathrm{NS}^{*},{ }^{* *},{ }^{* * *}$ \\
\hline \multicolumn{5}{|l|}{ Dyspnea status, mMRC } \\
\hline Grade $0-2, \%$ & 0 & 0 & 0 & - \\
\hline Grade 3, \% & 37.5 & 34.2 & 32.2 & $\mathrm{NS}^{*},{ }^{* *}, * * *$ \\
\hline Grade 4, \% & 62.5 & 65.8 & 67.8 & $\mathrm{NS}^{*},{ }^{* *},{ }^{* * *}$ \\
\hline $\begin{array}{l}\text { Hospitalization, times/previous } \\
\text { year }\end{array}$ & $2.5 \pm 1.5$ & $2.2 \pm 1.3$ & $2.7 \pm 1.8$ & $N S^{*},{ }^{* *},{ }^{* * *}$ \\
\hline \multicolumn{5}{|l|}{ Transthoracic Echocardiography } \\
\hline Systolic PAP, mmHg & $58 \pm 8$ & $60 \pm 9$ & $59 \pm 7$ & $\mathrm{NS}^{*},{ }^{* *},{ }^{* * *}$ \\
\hline \multicolumn{5}{|l|}{ Lung Function Testing } \\
\hline $\mathrm{FEV}_{1}, \%$ & $42 \pm 7$ & $39 \pm 9$ & $41 \pm 8$ & $\mathrm{NS}^{*},{ }^{* *}, * * *$ \\
\hline FEV1/FVC, \% & $54 \pm 8$ & $52 \pm 6$ & $53 \pm 5$ & $\mathrm{NS}^{*},{ }^{* *},{ }^{* * *}$ \\
\hline TLC, \% & $114 \pm 14$ & $113 \pm 22$ & $117 \pm 16$ & $N S^{*}, * *, * * *$ \\
\hline $\mathrm{RV}, \%$ & $177 \pm 16$ & $175 \pm 21$ & $178 \pm 19$ & $\mathrm{NS}^{*},{ }^{* *}, * * *$ \\
\hline FRC, \% & $162 \pm 18$ & $166 \pm 21$ & $165 \pm 22$ & $\mathrm{NS}^{*},{ }^{* *}, * * *$ \\
\hline DLCO, \% & $44 \pm 13$ & $43 \pm 12$ & $42 \pm 14$ & $\mathrm{NS}^{*},{ }^{* *},{ }^{* * *}$ \\
\hline \multicolumn{5}{|c|}{ Cardiopulmonary Exercise Testing } \\
\hline Oxygen consumption, $\% \mathrm{VO}_{2} \max$ & $34 \pm 8$ & $32 \pm 10$ & $36 \pm 9$ & $\mathrm{NS}^{*},{ }^{* *},{ }^{* * *}$ \\
\hline \multicolumn{5}{|l|}{6 Minutes' Walk Test } \\
\hline 6MWD, meters & $212 \pm 86$ & $224 \pm 74$ & $217 \pm 95$ & $N S^{*}, * *, * * *$ \\
\hline
\end{tabular}

BMI: Body Mass Index; mMRC: modified British Medical Research Council; PAP: Pulmonary Arterial Pressure; FEV1: Forced Expiratory in One Second; FVC: Forced Vital Capacity; TLC: Total Lung Function; RV: Residual Volume; FRC: Functional Residual Capacity; DLCO: Diffusing Capacity of the Lung for Carbon Monoxide; 6MWD: 6 Minutes Walking Distance.

*Group 1 vs. Group 2; **Group 1 vs. Group 3; *** Group 2 vs. Group 3.

NS: No significantly difference with $\mathrm{P}>0.05$.

Table 1: Clinical and functional characteristics of study subjects at inclusion.

\begin{tabular}{|c|c|c|c|c|}
\hline Parameters & $\begin{array}{l}\text { Group } 1 \\
\mathrm{~N}=32\end{array}$ & $\begin{array}{l}\text { Group } 2 \\
\mathrm{~N}=35\end{array}$ & $\begin{array}{l}\text { Group } 3 \\
\mathrm{~N}=31\end{array}$ & $\mathbf{P}$ \\
\hline \multicolumn{5}{|l|}{ Treatment } \\
\hline Conventional treatment, \% & 100 & 100 & 100 & NC \\
\hline Long-term oxygen therapy, \% & 100 & 100 & 100 & NC \\
\hline Sildenafil, \% & 0 & 100 & 100 & NC \\
\hline Sildenafil+Simvastatin, \% & 0 & 0 & 100 & NC \\
\hline \multicolumn{5}{|l|}{ Dyspnea Status, mMRC } \\
\hline Grade $0-2, \%$ & 0 & 0 & 0 & NC \\
\hline Grade 3, \% & 53.6 & 55.4 & 62.7 & $\mathrm{NS}^{*} ;<0.05^{* *},{ }^{* * *}$ \\
\hline Grade 4, \% & 46.4 & 44.6 & 37.3 & $\mathrm{NS}^{*} ;<0.05^{* *},{ }^{* * *}$ \\
\hline Hospitalization During 3 Months, \% & 9.3 & 8.5 & 9.6 & $\mathrm{NS}^{*},{ }^{* *}, * * *$ \\
\hline \multicolumn{5}{|l|}{ Transthoracic Echocardiography } \\
\hline Systolic PAP, mmHg & $46 \pm 10$ & $41 \pm 9$ & $39 \pm 7$ & $<0.05^{*},{ }^{* *} ; \mathrm{NS}^{* * *}$ \\
\hline \multicolumn{5}{|l|}{ Lung Function Testing } \\
\hline FEV1, \% & $46 \pm 12$ & $45 \pm 13$ & $49 \pm 11$ & $\mathrm{NS}^{*},{ }^{* *},{ }^{* * *}$ \\
\hline DLCO, \% & $56 \pm 13$ & $64 \pm 11$ & $63 \pm 12$ & $<0.05^{*},{ }^{* *} ; N S^{* * *}$ \\
\hline \multicolumn{5}{|c|}{ Cardiopulmonary Exercise Testing } \\
\hline Oxygen consumption, $\% \mathrm{VO}_{2} \max$ & $36 \pm 7$ & $34 \pm 9$ & $37 \pm 8$ & $\mathrm{NS}^{*},{ }^{* *},{ }^{* * *}$ \\
\hline \multicolumn{5}{|l|}{6 Minutes' Walk Test } \\
\hline 6MWD, meters & $217 \pm 92$ & $229 \pm 82$ & $225 \pm 91$ & $\mathrm{NS}^{*},{ }^{* *},{ }^{* * *}$ \\
\hline
\end{tabular}

Conventional treatment: LABA (long-acting beta2-agonists)+ICS (inhaled corticosteroids) [Seretide ${ }^{\circledR}$ (Salmeterol/Fluticasone)]+LAMA (long-acting muscarinic antagonists) [Spiriva ${ }^{\circledR}$ (Tiotropium)], and SABA as needed [Ventoline ${ }^{\circledR}$ (Albuterol)] mMRC: modified British Medical Research Council (mMRC) Questionnaire; PAP: pulmonary arterial pressure; FEV1: forced expiratory in one second; DLCO: diffusing capacity of the lung for carbon monoxide; 6MWD: 6 minutes walking distance.

*Group 1 vs. Group 2; **Group 1 vs. Group 3; ***Group 2 vs. Group 3 NC: Non comparison; NS: No significantly difference with $P>0.05$.

Table 2: Clinical and functional characteristics of study subjects after 3 months with treatment.

sildenafil $100 \mathrm{mg}$ ) and Group 1 (treated with conventional therapy combined with LTOT alone; Table 2).

The mean systolic PAPs in patients from Group 2 and Group 3 were significantly lower than that in Group 1 after 3 months of treatment $(41$ $\pm 9 \mathrm{mmHg}$ and $39 \pm 7 \mathrm{mmHg}$ vs. $46 \pm 10 \mathrm{mmHg} ; \mathrm{P}<0.05$ and $\mathrm{P}<0.05$; respectively; Table 2). There was no significant difference between Group 2 and Group 3 ( $>>0.05$; Table 2). Although after 3 months, the mean value of $\mathrm{FEV}_{1}$ was not significantly different between three groups, the mean values of DLCO in patients from Group 2 and Group 3 were significantly higher than that in Group $1(64 \pm 11 \%$ and $63 \pm$ $12 \%$ vs. $56 \pm 13 \% ; \mathrm{P}<0.05$ and $\mathrm{P}<0.05$; respectively; Table 2$)$. There were no significant differences between 3 groups for $\mathrm{VO}_{2}$ max and 6MWD (Table 2)

\section{Effect of sildenafil combined with simvastatin and LTOT in association with conventional treatment at 6 months}

The present study showed that patients from Group 2 and Group 3 had the percentage of mMRC grade 3 was significant higher and mMRC grade 4 was significant lower than Group 1 (62.7\% and 66.5\% vs. $56.3 \% ; \mathrm{P}<0.05$ and $\mathrm{P}<0.05$; respectively; $37.3 \%$ and $33.5 \%$ vs. $43.7 \%$; $\mathrm{P}<0.05$ and $\mathrm{P}<0.05$; respectively; Table 3 ), while there was no significant difference between Group 2 and Group 3 (Table 3).

After 6 months, the mean systolic PAP in patients of Group 2 and Group 3 were significantly lower than that in Group $1(40 \pm 7 \mathrm{mmHg}$ and $38 \pm 9 \mathrm{mmHg}$ vs. $45 \pm 8 \mathrm{mmHg} ; \mathrm{P}<0.05$ and $\mathrm{P}<0.05$; respectively; Table 3). However, there were no significant differences between Group 2 and Group 3 (P>0.05; Table 3 ). The mean values of FEV and DLCO were not significantly different between 3 groups after 6 
Citation: Tran-Van H, Vo-Thi-Kim A, Tran-Ngoc T, Duong-Quy S (2017) Comparison of Long Term Oxygen-Therapy (LTOT) and LTOT Combined with Sildenafil and Simvastatin in the Treatment of Severe Chronic Obstructive Pulmonary (COPD) with Hypoxia at Rest and Severe Pulmonary Arterial Hypertension. J Vasc Med Surg 5: 324. doi: 10.4172/2329-6925.1000324

months (Table 3). The oxygen consumption $\left(\mathrm{VO}_{2} \max \right)$ and 6MWD in patients from Group 3 were significantly higher than that in patients with Group 1 and $2(41 \pm 7 \%$ vs $37 \pm 9 \%$ and $36 \pm 8 \% ; \mathrm{P}<0.05$ and $\mathrm{P}<0.05$; respectively; $275 \pm 74 \mathrm{~m}$ vs. $223 \pm 87$ and $231 \pm 92 \%$; $\mathrm{P}<0.05$ and $\mathrm{P}<0.05$; respectively; Table 3 )

\section{Effect of treatment on systolic PAP, DLCO, and $\mathrm{VO}_{2}$ max after 3 months and 6 months in patients from three groups}

The results of present study showed that, in Group 1 (treated with conventional therapy combined with LTOT), systolic PAP were significantly decreased after 3 month and 6 months $(46 \pm 10 \mathrm{mmHg}$ and $45 \pm 8 \mathrm{mmHg}$ vs $58 \pm 8 \mathrm{mmHg} ; \mathrm{P}<0.01$ and $\mathrm{P}<0.01$; respectively; Figure $1 \mathrm{~A}$ ), but there was no significant difference between 3 months and 6 months ( $46 \pm 10 \mathrm{mmHg}$ vs $45 \pm 8 \mathrm{mmHg}$; $>>0.05$; Figure $1 \mathrm{~A}$ ). The mean DLCO were significantly increased after 3 months and 6 months in this group $(56 \pm 13 \%$ and $61 \pm 6 \%$ vs $44 \pm 13 \% ; \mathrm{P}<0.05$ and $\mathrm{P}<0.01$; respectively; Figure $1 \mathrm{~A})$. There was no significant difference of DLCO after 3 months and 6 months $(\mathrm{P}>0.05)$. The mean $\mathrm{VO}_{2}$ max was not significant differences at inclusion and after 3 to 6 months (Figure 1A).

In Group 2 (treated with conventional therapy, LTOT, and sildenafil), the mean systolic PAP were significantly decreased after 3 month and 6 months $(41 \pm 9 \mathrm{mmHg}$ and $40 \pm 7 \mathrm{mmHg}$ vs $60 \pm 9$ mmHg; $\mathrm{P}<0.05$ and $\mathrm{P}<0.01$; respectively; Figure $1 \mathrm{~B})$. That was not significantly different between 3 and 6 months $(41 \pm 9 \mathrm{mmHg}$ vs 40 $\pm 7 \mathrm{mmHg}$; $>0.05$; Figure 1B). The mean DLCO were significantly increased after 3 and 6 months in Group $2(64 \pm 11 \%$ and $65 \pm 9 \%$ vs $43 \pm 12 \% ; \mathrm{P}<0.01$ and $\mathrm{P}<0.01$; respectively; Figure $1 \mathrm{~B})$. There was no significant difference of the mean DLCO after 3 months and 6 months $\left(\mathrm{P}>0.05\right.$; Figure 1B). The mean $\mathrm{VO}_{2}$ max was not significant differences

\begin{tabular}{|c|c|c|c|c|}
\hline Parameters & $\begin{array}{l}\text { Group } 1 \\
\mathrm{~N}=32\end{array}$ & $\begin{array}{l}\text { Group } 2 \\
\mathrm{~N}=35\end{array}$ & $\begin{array}{l}\text { Group } 3 \\
\mathrm{~N}=31\end{array}$ & $\mathbf{P}$ \\
\hline \multicolumn{5}{|l|}{ Treatment } \\
\hline Conventional treatment, $\%$ & 100 & 100 & 100 & NC \\
\hline Long-term oxygen therapy, \% & 100 & 100 & 100 & NC \\
\hline Sildenafil, \% & 0 & 100 & 100 & NC \\
\hline Sildenafil+Simvastatin, \% & 0 & 0 & 100 & NC \\
\hline \multicolumn{5}{|l|}{ Dyspnea status, mMRC } \\
\hline Grade $0-2, \%$ & 0 & 0 & 0 & NC \\
\hline Grade 3, \% & 56.3 & 62.7 & 66.5 & $<0.05^{*},{ }^{* *} ; \mathrm{NS}^{* * *}$ \\
\hline Grade 4, \% & 43.7 & 37.3 & 33.5 & $<0.05^{*},{ }^{* *} ; \mathrm{NS}^{* * *}$ \\
\hline Hospitalization, \% & 6.2 & 5.7 & 6.4 & $\mathrm{NS}^{*}, * *, * * *$ \\
\hline \multicolumn{5}{|l|}{ Transthoracic Echocardiography } \\
\hline Systolic PAP, mmHg & $45 \pm 8$ & $40 \pm 7$ & $38 \pm 9$ & $<0.05^{*},{ }^{* *} ; \mathrm{NS}^{* * *}$ \\
\hline \multicolumn{5}{|l|}{ Lung Function Testing } \\
\hline $\mathrm{FEV}_{1}, \%$ & $48 \pm 8$ & $50 \pm 9$ & $49 \pm 10$ & $\mathrm{NS}^{*},{ }^{* *},{ }^{* * *}$ \\
\hline DLCO, \% & $61 \pm 6$ & $65 \pm 9$ & $64 \pm 8$ & $\mathrm{NS}^{*},{ }^{* *},{ }^{* \star *}$ \\
\hline \multicolumn{5}{|c|}{ Cardiopulmonary Exercise Testing } \\
\hline Oxygen consumption, $\% \mathrm{VO}_{2} \max$ & $37 \pm 9$ & $36 \pm 8$ & $41 \pm 7$ & $\mathrm{NS}^{*} ;<0.05^{\star *}, * * *$ \\
\hline \multicolumn{5}{|c|}{6 Minutes' Walk Test } \\
\hline 6MWD, meters & $223 \pm 87$ & $231 \pm 92$ & $275 \pm 74$ & $\mathrm{NS}^{*} ;<0.05^{* *},{ }^{* * *}$ \\
\hline
\end{tabular}

Conventional treatment: LABA (long-acting beta ${ }_{2}$-agonists)+ICS (inhaled corticosteroids) [Seretide ${ }^{\circledR}$ (Salmeterol/Fluticasone)] + LAMA (long-acting muscarinic antagonists) [Spiriva ${ }^{\circledR}$ (Tiotropium)], and SABA as needed [Ventoline ${ }^{\circledR}$ (Albuterol)]; mMRC: modified British Medical Research Council (mMRC) Questionnaire; PAP: pulmonary arterial pressure; $F_{1}$ : forced expiratory in one second; DLCO: diffusing capacity of the lung for carbon monoxide; 6MWD: 6 minutes walking distance.

*Group 1 vs. Group 2; **Group 1 vs. Group 3; ** Group 2 vs. Group 3

NC: Non comparison; NS: No significantly difference with $P>0.05$.

Table 3: Clinical and functional characteristics of study subjects after 6 months with treatment. at inclusion and after 3 to 6 months in patients from this group (Figure 1B).

The present study showed that in Group 3 (treated with conventional therapy, LTOT, sildenafil, and simvastatin), the mean systolic PAP were significantly decreased after 3 month and 6 months $(39 \pm 7 \mathrm{mmHg}$ and $38 \pm 9 \mathrm{mmHg}$ vs $59 \pm 7 \mathrm{mmHg} ; \mathrm{P}<0.01$ and
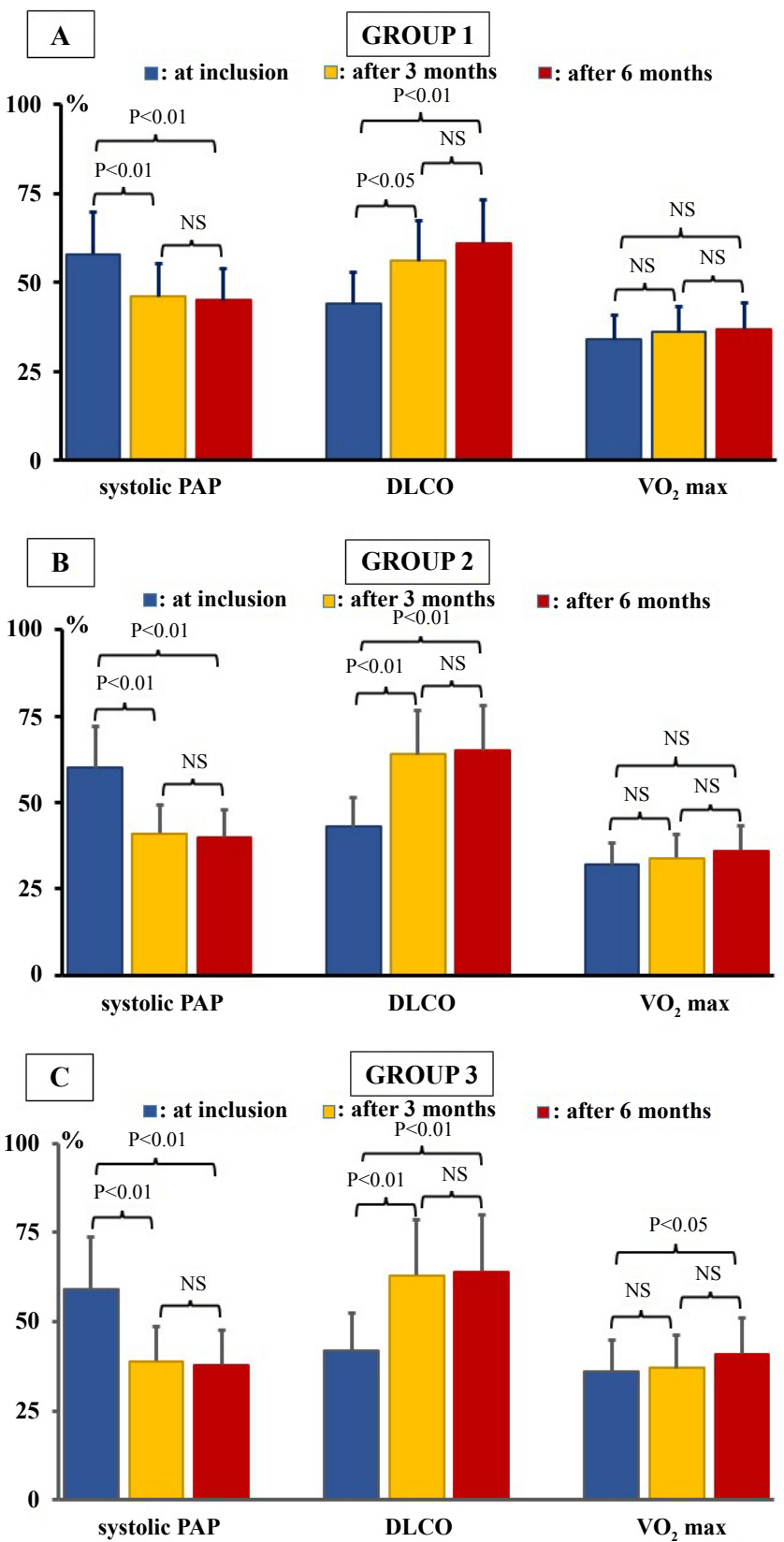

Figure 1: Efficacy of treatment on systolic PAP, DLCO, and $\mathrm{VO}_{2}$ max after 3-6 months in patients from three groups.

1A: Group 1, including the patients treated with conventional and long-term oxygen therapy (LTOT); 1B: Group 2, including the patients treated with conventional therapy, LTOT, and combined with Sildenafil; 1C: Group 3 including the patients treated with conventional therapy, LTOT, Sildenafil, and Simvastatin.

PAP: Pulmonary Arterial Pressure; DLCO: Diffusing Capacity of the Lung for Carbon Monoxide; NS: No significantly difference with $P>0.05$. 
Citation: Tran-Van H, Vo-Thi-Kim A, Tran-Ngoc T, Duong-Quy S (2017) Comparison of Long Term Oxygen-Therapy (LTOT) and LTOT Combined with Sildenafil and Simvastatin in the Treatment of Severe Chronic Obstructive Pulmonary (COPD) with Hypoxia at Rest and Severe Pulmonary Arterial Hypertension. J Vasc Med Surg 5: 324. doi: 10.4172/2329-6925.1000324

$\mathrm{P}<0.01$; respectively; Figure $1 \mathrm{C})$. In this group, the mean DLCO were significantly increased after 3 and 6 months $(\mathrm{P}<0.01$ and $\mathrm{P}<0.01$; respectively; Figure $1 \mathrm{C})$. There was no significant difference between after 3 months and 6 months $(\mathrm{P}>0.05$; Figure $1 \mathrm{C})$. However, the mean $\mathrm{VO}_{2}$ max was significantly increased between 6 months and at inclusion in patients from Group 3 (Figure 1C)

\section{Discussion}

The results of present study showed that in patients with severe COPD having hypoxia at rest, the treatment with sildenafil alone (Group 2) and sildenafil associated with simvastatin (Group 3) in combined with conventional and long-term oxygen therapy (LTOT) was better than that by using only conventional therapy and LTOT (Group 1) to ameliorate a dyspnea status after 6 months of follow-up (Tables 2 and 3). Especially, the patients from Group 3 had the significant amelioration of dyspnea status after 3 months confirming by the decrease of percentage of patients with $\mathrm{mMRC}$ grade 4 and the increase of mMRC grade 3 (Table 2). However, after 6 months, the patients from Group 2 and Group 3 had no significant differences of dyspnea status. It suggests that the effect of sildenafil or sildenafil combined with simvastatin was similar after 6 months follow up. Sildenafil associated with LTOT was better sildenafil alone in ameliorating dyspnea status might be due to its effect on vascular modulation by reducing pre- and post-load for right heart in severe COPD patients with hypoxia at rest.

Until now, the exact mechanism of sildenafil or other phosphodiesterase-5 (PDE-5) inhibitors on dyspnea status of patients with COPD has not been well demonstrated [21,22]. However, its role in amelioration of dyspnea status in patients with other cardio-respiratory diseases has been described by previous studies [23,24]. Sildenafil might decrease dyspnea by its effect on pulmonary arterial vasodilation via increasing cyclic guanosine monophosphate (cGMP) produced by nitric oxide (NO) $[25,26]$. Although the effect of simvastatin in severe COPD has been demonstrated previously [27], the combination of sildenafil and simvastatin in reducing dyspnea status in these patients has not been clarified. It might be due to the effect of this combined treatment on pulmonary arterial pressure (PAP).

The present study showed that while the mean PAPs were significantly reduced in patients from three groups after 3 months and 6 months within treatment (Figures 1A-1C; Tables 1-3), the patients from Group 2 and Group 3 had the level of systolic PAP decreasing more significant than that in Group 1. This result suggest that LTOT (long-term oxygen therapy) alone or in combination with sildenafil or sildenafil and simvastatin may be also effective in treatment of PAP in patients with severe COPD and pulmonary arterial hypertension $(\mathrm{PAH})$ and it may be more efficacy with combined treatment. Although the use of LTOT has been recommended strongly in patients with severe COPD having hypoxia at rest or for those with severe $\mathrm{PAH}$, especially for severe COPD with PAH $[20,28,29]$, the effect of LTOT combined with sildenafil or sildenafil associated with simvastatin has not been clearly demonstrated.

In patients with COPD, LTOT has been prescribed when oxygen saturation at rest less than $88 \%$ or $90 \%$ for those with congestive heart failure $[20,28]$. In patients with severe COPD, LTOT prevents not only the progression to right heart failure but also the survival free of acute exacerbation [29]. Moreover, in patients with cigarette smokinginduced COPD having hypoxia at rest, even though in acting smoking with normal lung function, LTOT might prevent hypoxia-related endothelial dysfunction and pulmonary vasoconstriction with the evolution toward pulmonary vascular remodelling and PAP $[30,31]$.
The result of our study showed that in Group 1, the mean systolic PAP was significantly reduced after 3 months treated with conventional therapy (bronchodilators and inhaled corticosteroids) associated with LTOT and it was similar to LTOT combined with sildenafil or with sildenafil plus simvastatin (Tables 2 and 3; Figures 1A-1C). However, the combined treatment of LTOT with sildenafil or sildenafil associated with simvastatin was more efficacy in the reduction of PAP measured by transthoracic echocardiography (EET) (Tables 2 and 3). The role of sildenafil in treatment of PAH has been described previously but its role in COPD patients with PAH has not been well demonstrated $[22,24]$. In general, PDE-5 inhibitors could reduce PAP by the effect on vasodilation. Recently, the role of simvastatin (HMG CoA reductase inhibitor) in $\mathrm{PAH}$ has been studied. Statin is ubiquitous drug and also non-selective RhoA/Rho-kinase inhibitor. Although the effect of statin in amelioration of lung function in patients with COPD has been described recently, its role in the treatment of PAH has been still discussed. Simvastatin might inhibit the hypoxiainduced vasoconstriction mediated by RhoA/Rho-kinase [32]. Recent study realized by our group showed the activity of RhoA/Rho-kinase signaling pathway had been increased in smokers and in smokers with COPD [30]. It suggests that statin might be a potential additional treatment in severe COPD with hypoxia at rest.

Interestingly, the present study showed that LTOT alone or combined with sildenafil or sildenafil plus simvastatin in all COPD patients treated with conventional therapy (long-acting beta agonists+inhaled corticosteroids+long-acting muscarinic antagonists) also ameliorated the decrease of DLCO after 3 months and 6 months (Figures 1A-1C). This effect was more significantly in patients treated with LTOT combined with sildenafil and simvastatin (Tables 2 and 3). This result suggests that in COPD patients with hypoxia at rest, the use of LTOT might correct a ventilation - perfusion imbalance frequently presented in COPD, due to hypoventilation or hypoperfusion [33] However, the results of present study showed that oxygen consumption $\left(\mathrm{VO}_{2} \max \right)$ and 6 minutes walking distances were significantly increased only in COPD patients treated with LTOT combined with sildenafil or sildenafil associated with simvastatin (Tables 2 and 3). It suggests that the use of these drugs might protect patients with severe COPD having PAH from physical exercise. With a small number of patients and short-term follow-up, the use of transthoracic echocardiography as an only criteria for diagnosis of $\mathrm{PAH}$, and the lack of right heart catheterization to confirm the diagnosis of $\mathrm{PAH}$, the present study had some limitations to advise the routine use of sildenafil and simvastatin in patients with severe COPD having hypoxia at rest. With the shortterm follow-up, the other additional limitation of the present study was related to the pharmacokinetic interactions among the prescribed drugs and the complications of these drugs for long-term treatment.

\section{Conclusion}

Pulmonary arterial hypertension is a frequent comorbidity in patients with severe COPD. Long-term oxygen therapy in association with conventional therapy as recommended by GOLD is still the best choice for patients with hypoxia at rest. The role of other additional drugs such as PDE-5 inhibitors and HMG CoA reductase inhibitors should be evaluated by more studies.

\section{Acknowledgement}

The authors would like to thank all the Member of Clinical Research Unit of Lam Dong Medical College for their valuable contribution to this study.

\section{Disclosure}

The authors report no conflicts of interest in this study. 
Citation: Tran-Van H, Vo-Thi-Kim A, Tran-Ngoc T, Duong-Quy S (2017) Comparison of Long Term Oxygen-Therapy (LTOT) and LTOT Combined with Sildenafil and Simvastatin in the Treatment of Severe Chronic Obstructive Pulmonary (COPD) with Hypoxia at Rest and Severe Pulmonary Arterial Hypertension. J Vasc Med Surg 5: 324. doi: 10.4172/2329-6925.1000324

\section{References}

1. Lozano R, Naghavi M, Foreman K, Lim S, Shibuya K, et al. (2012) Global and regional mortality from 235 causes of death for 20 age groups in 1990 and 2010: a systematic analysis for the Global Burden of Disease Study 2010. Lancet 380: 2095-2128.

2. Vos T, Flaxman AD, Naghavi M, Lozano R, Michaud C, et al. (2012) Years lived with disability (YLDs) for 1160 sequelae of 289 diseases and injuries 1990 2010: a systematic analysis for the Global Burden of Disease Study 2010 Lancet 380: 2163-2196.

3. Eisner MD, Anthonisen N, Coultas D, Kuenzli N, Perez-Padilla R, et al. (2010) An official American Thoracic Society public policy statement: Novel risk factors and the global burden of chronic obstructive pulmonary disease. Am J Respir Crit Care Med 182: 693-718.

4. Salvi SS, Barnes PJ (2009) Chronic obstructive pulmonary disease in nonsmokers. Lancet 374: 733-743.

5. Duong-Quy S, Hua-Huy T, Mai-Huu-Thanh B, Doan-Thi-Quynh N, Le-Quang K, et al. (2009) Early detection of smoking related chronic obstructive pulmonary disease in Vietnam. Rev Mal Respir 26: 267-274.

6. Wrobel JP, Thompson BR, Williams TJ (2012) Mechanisms of pulmonary hypertension in chronic obstructive pulmonary disease: a pathophysiologic review. J Heart Lung Transplant 31: 557-564.

7. Chaouat A, Bugnet AS, Kadaoui N, Schott R, Enache I, et al. (2005) Severe pulmonary hypertension and chronic obstructive pulmonary disease. Am J Respir Crit Care Med 172:189-194.

8. Chaouat A, Naeije R, Weitzenblum E (2008) Pulmonary hypertension in COPD. Eur Respir J 32: 1371-1385.

9. Barberà JA, Blanco I (2009) Pulmonary hypertension in patients with chronic obstructive pulmonary disease: advances in pathophysiology and management. Drugs 69: 1153-1171.

10. Arian A, Moghadam SG, Kazemi T, Haiihosseini M (2017) The Effects of Statins on Pulmonary Artery Pressure in Patients with Chronic Obstructive Pulmonary Disease: A Randomized Controlled Trial. J Res Pharm Pract 6: 27-30.

11. Cordle A, Koenigsknecht-Talboo J, Wilkinson B, Limpert A, Landreth G (2005) Mechanisms of statin-mediated inhibition of small G-protein function. J Bio Chem 280: 34202-34209.

12. Cranston JM, Crockett AJ, Moss JR, Alpers JH (2005) Domiciliary oxygen for chronic obstructive pulmonary disease. Cochrane Database Syst Rev.

13. Long-term Oxygen Treatment Trial Research Group (2016) A randomized tria of long-term oxygen for COPD with moderate desaturation. NEJM 375: 1617-1627.

14. Single breath carbon monoxide diffusing capacity (transfer factor) Recommendations for a standard technique. Statement of the American Thoracic Society (1987) Am Rev Respir Dis 136: 1299-1307.

15. Macintyre N, Crapo RO, Viegi G, Johnson DC, Van der Grinten CP, et al. (2005) Standardization of the single-breath determination of carbon monoxide uptake in the lung. Eur Respir J 26: 720-735

16. American Thoracic Society ATS Committee on Proficiency Standards for Clinical Pulmonary Function Laboratories (2002) ATS statement: guidelines for the six-minute walk test. Am J Respir Crit Care Med 166: 111-117.

17. Guazzi M, Adams V Conraads V, Halle M, Mezzani A et al. (2012) EACPR AHA Scientific Statement. Clinical recommendations for cardiopulmonary exercise testing data assessment in specific patient populations. Circulation 126: $2261-2274$

18. Hachulla E, Gressin V, Guillevin L, Carpentier P, Diot E, et al. (2005) Early detection of pulmonary arterial hypertension in systemic sclerosis: A French nationwide prospective multicenter study. Arthritis Rheum 52: 3792-3800.

19. Grunig E, Weissmann S, Ehlken N, Fijalkowska A, Fischer C, et al. (2009) Stress Doppler echocardiography in relatives of patients with idiopathic and familial pulmonary arterial hypertension: results of a multicenter European analysis of pulmonary artery pressure response to exercise and hypoxia. Circulation 119: 1747-1757.

20. Global Strategy for Diagnosis, Management and Prevention of COPD (GOLD) (2015). Last accessed: January 24th 2016.

21. Girard A, Jouneau S, Chabanne C, Khouatra C, Lannes M, et al. (2015) Severe pulmonary hypertension associated with COPD: hemodynamic improvement with specific therapy. Respiration. 90: 220-228.

22. Vitulo P, Stanziola A, Confalonieri M, Libertucci D, Oggionni T, et al. (2017) Sildenafil in severe pulmonary hypertension associated with chronic obstructive pulmonary disease: A randomized controlled multicenter clinical trial. J Heart Lung Transplant 36: 166-174.

23. Anand A, Srivastava N, Barwad P, Ramakrishnan S, Roy A, et al. (2014) Dyspnea in Eisenmenger syndrome and its amelioration by sildenafil: role of $J$ receptors. Int J Cardiol 174: 574-578.

24. Kumar U, Sankalp G, Sreenivas V, Kaur S, Misra D (2013) Prospective open-label, uncontrolled pilot study to study safety and efficacy of sildenafil in systemic sclerosis-related pulmonary artery hypertension and cutaneous vascular complications. Rheumatol Int 33: 1047-1052.

25. Duong-Quy S (2016) Physiopathology of Pulmonary Hypertension: from BioMolecular Mechanism to Target Treatment. J Vasc Med Surg.

26. Duong-Quy S, Rivière S, Bei Y, Duong-Ngo C, Le-Dong NN, et al. (2012 Pulmonary hypertension: from molecular pathophysiology to haemodynamic abnormalities. Rev Mal Respir 29: 956-970.

27. Criner GJ, Connett JE, Aaron SD, Lazarus SC, Bailey WC, et al. (2014) Simvastatin for the prevention of exacerbations in moderate-to-severe COPD. N Engl J Med 370: 2201-2210.

28. Global Strategy for Diagnosis, Management and Prevention of COPD (GOLD) 2015. Last accessed: May 13th 2016.

29. Galiè N, Humbert M, Vachiery JL, Gibbs S, Lang I, et al. (2015) 2015 ESC/ ERS Guidelines for the diagnosis and treatment of pulmonary hypertension: The Joint Task Force for the Diagnosis and Treatment of Pulmonary Hypertension of the European Society of Cardiology (ESC) and the European Respiratory Society (ERS): Endorsed by: Association for European Paediatric and Congenital Cardiology (AEPC), International Society for Heart and Lung Transplantation (ISHLT). Eur Respir J. 46: 903-975.

30. Duong-Quy S, Dao P, Hua-Huy T, Guilluy C, Pacaud P, et al. (2011) Increased Rho-kinase expression and activity and pulmonary endothelial dysfunction in smokers with normal lung function. Eur Respir J 37: 349-355.

31. Duong-Quy S (2013) Chronic Smoking and Vascular Disease: What Can we Hope for the Future? J Vasc Med Surg.

32. Duong-Quy S, Bei Y, Liu Z, Dinh-Xuan AT (2013) Role of Rho-kinase and its inhibitors in pulmonary hypertension. Pharmacol Ther 137: 352-364

33. Vonbank K, Ziesche R, Higenbottam TW, Stiebellehner L, Petkov V, et al (2003) Controlled prospective randomised trial on the effects on pulmonary haemodynamics of the ambulatory long term use of nitric oxide and oxygen in patients with severe COPD. Thorax 58: 289-293. 